\title{
Clinical and genetic characterization of Portuguese patients with pseudohypoparathyroidism type Ib
}

\author{
Branca Maria Cavaco • Rute Alexandra Tomaz • \\ Fernando Fonseca - Mário Rui Mascarenhas • \\ Valeriano Leite $\cdot$ Luís Gonçalves Sobrinho
}

Received: 4 January 2010/Accepted: 8 March 2010/Published online: 30 March 2010

(C) Springer Science+Business Media, LLC 2010

\begin{abstract}
Patients with pseudohypoparathyroidism type $\mathrm{Ib}$ (PHP-Ib) present hypocalcemia and hyperphosphatemia, as a consequence of a resistance to PTH action, through its G-protein-coupled receptor, in the renal tubules. This resistance results from tissue-specific silencing of the G-protein alpha-subunit $\left(\mathrm{G}_{\mathrm{s}} \alpha\right)$, due to imprinting disruption of its encoding locus-GNAS. In familial PHP-Ib, maternally inherited deletions at the STX16 gene are associated to a regional GNAS methylation defect. In sporadic PHP$\mathrm{Ib}$, broad methylation changes at GNAS arise from unknown genetic causes. In this study, we describe the clinical presentation of PHP-Ib in four Portuguese patients
\end{abstract}

Branca Maria Cavaco and Rute Alexandra Tomaz contributed equally to this work.

B. M. Cavaco $(\bowtie) \cdot$ R. A. Tomaz $\cdot$ V. Leite

Centro de Investigação de Patobiologia Molecular, CIPM,

Instituto Português de Oncologia de Lisboa Francisco Gentil,

1099-023 Lisbon, Portugal

e-mail: bcavaco@ipolisboa.min-saude.pt

F. Fonseca

Serviço de Endocrinologia, Hospital Curry Cabral,

1069-639 Lisbon, Portugal

M. R. Mascarenhas

Clínica Universitária de Endocrinologia, Faculdade de Medicina de Lisboa, 1600-190 Lisbon, Portugal

V. Leite $\cdot$ L. G. Sobrinho

Serviço de Endocrinologia, Instituto Português

de Oncologia de Lisboa Francisco Gentil, 1099-023 Lisbon,

Portugal

B. M. Cavaco - R. A. Tomaz - V. Leite - L. G. Sobrinho Centro de Estudos de Doenças Crónicas, CEDOC, Faculdade de Ciências Médicas, Universidade Nova de Lisboa,

1169-056 Lisbon, Portugal (two of whom were siblings), and provide further insight for the management of patients with this disease. The diagnosis of PHP-Ib was made after detection of GNAS imprinting defects in each of the cases. In the siblings, a regional GNAS methylation change resulted from a known $3.0 \mathrm{~kb}$ STX16 deletion. In the other two patients, the broad methylation defects at GNAS, which were absent in their relatives, resulted from genetic alterations that remain to be identified. We report the first clinical and genetic study of Portuguese patients with PHP-Ib. The genetic identification of a hereditary form of this rare disease allowed an early diagnosis, and may prevent hypocalcemia-related complications.

Keywords Genomic Imprinting $\cdot \mathrm{G}_{\mathrm{s}} \alpha \cdot$ Hypocalcemia . Pseudohypoparathyroidism $\cdot$ Syntaxin 16

\section{Introduction}

Pseudohypoparathyroidism (PHP) describes a heterogeneous group of disorders characterized by hypocalcemia and hyperphosphatemia, resulting from renal resistance to PTH $[1,2]$.

Pseudohypoparathyroidism type Ia (PHP-Ia; MIM 103580 ) is characterized by end-organ resistance to $\mathrm{PTH}$, and to other hormones also signaling through G-proteincoupled receptors, and a combination of defects termed "Albright Hereditary Osteodystrophy" (AHO), characterized by rounded face, obesity, short stature, brachydactyly, and mental retardation [3]. These patients exhibit a decrease in the bioactivity of $\mathrm{G}_{\mathrm{s}} \alpha$, the alpha stimulatory subunit of G-protein, as the result of inactivating mutations in its encoding gene (GNAS; MIM 139320), located at chromosome 20q13.3. 
Patients with pseudohypoparathyroidism type Ib (PHPIb; MIM 603233) show renal resistance to PTH due to low/ absent $\mathrm{G}_{\mathrm{s}} \alpha$ activity, associated to the disruption of the GNAS locus imprinting. These patients show, occasionally, thyroid stimulating hormone (TSH) resistance and, typically lack AHO features [1]. The GNAS locus also encodes four additional transcripts, XL $\alpha$ s, NESP55, 1A (also referred as $\mathrm{A} / \mathrm{B}$ ), and antisense (AS), which are imprinted (Fig. 1) [4, 5]. The promoters and first exons of these four transcripts are located within individual differentially methylated regions (DMRs). AS, XL $\alpha$ s, and 1A are transcribed by the paternal allele, while NESP55 is transcribed by the maternal allele. The $\mathrm{G}_{\mathrm{s}} \alpha$ promoter is not methylated and the transcript is biallelically expressed in most tissues. However, in the proximal renal tubules, thyroid, anterior pituitary, and gonads, $\mathrm{G}_{\mathrm{s}} \alpha$ transcription from the paternal allele undergoes tissue-specific silencing, being expressed mainly by the maternal allele $[6,7]$.

PHP-Ib patients show loss of methylation at the maternal 1A DMR [8,9] and, apparently, this leads to a reduced/ absent $\mathrm{G}_{\mathrm{s}} \alpha$ expression in the proximal renal tubules [10]. This loss of methylation was associated to a maternally inherited $3.0 \mathrm{~kb}$ deletion in up to 30 families with autosomal dominant PHP-Ib [9, 11, 12], or a $4.4 \mathrm{~kb}$ deletion in one family [13], in the gene encoding syntaxin-16 (STX16; MIM 603666), located $200 \mathrm{~kb}$ upstream from GNAS. Two other families were shown to carry 4.0 and $4.7 \mathrm{~kb}$ deletions in the maternal NESP55 DMR, which were associated to methylation defects in the remaining GNAS DMRs [14]. These deletions at STX16 and NESP55 DMR comprise putative cis-acting elements that control GNAS imprinting. Broad methylation changes, resulting from yet unidentified genetic causes, were also observed in several patients with apparently sporadic PHP-Ib [9, 11, 12].

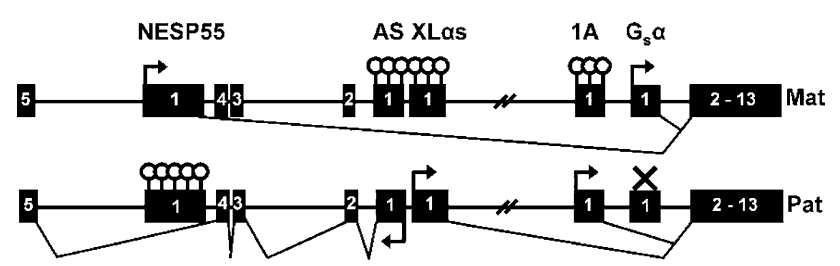

Fig. 1 General organization of the GNAS locus. Exons are indicated by closed boxes and introns are indicated by connecting lines. The human GNAS locus generates four different sense transcripts (NESP55, XL $\alpha$ s, 1A, and $\mathrm{G}_{\mathrm{s}} \alpha$ ), using four alternative first exons [1] that splice onto a common set of downstream exons (2-13). In addition, an antisense (AS) RNA is also produced. Promoters of the imprinted transcripts are located within individual differentially methylated regions (DMRs). Maternal (Mat) and paternal (Pat) epigenotypes are represented above and below, respectively. Methylation is indicated by open circles and transcriptionally active promoters are indicated by arrows in the direction of transcription. Tissue-specific silencing of $\mathrm{G}_{\mathrm{s}} \alpha$ is indicated by a black cross
We identified four Portuguese patients with clinical findings suggestive of PHP-Ib, and performed a comprehensive genetic and epigenetic analysis of the GNAS locus and STX16 gene.

\section{Patients and methods}

Patients

Patient 1 was a 6-year-old Caucasian girl, when, in 1990, she first presented at an Endocrinology Clinic because of precocious pubarche and excess weight. Her TSH levels were elevated at $11.8 \mathrm{mU} / \mathrm{l}$ (normal range [nr]: $0.5-$ $4.7 \mathrm{mU} / \mathrm{l}$ ), free thyroxine (FT4) was $1.1 \mathrm{ng} / \mathrm{dl}$ (nr: $0.8-$ $2.2 \mathrm{ng} / \mathrm{dl}$ ). Thyroid function normalized 1 year later. At the age of 11 , she was admitted to the hospital because of repeated episodes characterized by loss of consciousness, absence seizures, asymmetry of the mouth, loss of strength in the lower limbs, and other hypocalcemia-related manifestations. On admission, her serum calcium (Ca) was $4.8 \mathrm{mg} / \mathrm{dl}$ (nr: 8.9-10 mg/dl), phosphorus (P) was $10.5 \mathrm{mg} /$ dl (nr: 2.3-4.7 mg/dl), PTH was 566 pg/ml (nr: 12-65 pg/ $\mathrm{ml})$, and 1,25-dihydroxy vitamin $\mathrm{D}\left(1,25(\mathrm{OH})_{2} \mathrm{D}\right)$ was $38.5 \mathrm{pg} / \mathrm{ml}$ (nr: 18-62 pg/ml). Trousseau and Chvostek signs were positive. Computed tomography (CT) scan of the brain revealed bilateral calcifications of the basal nuclei (Table 1). She was given calcium phosphate and $1,25(\mathrm{OH})_{2} \mathrm{D}$. At the age of 18 , still on medication, her height was $1.63 \mathrm{~m}$ and weight was $58.4 \mathrm{~kg}(\mathrm{BMI}=22 \mathrm{~kg}$ / $\mathrm{m}^{2}$ ). Her Ca was $8.8 \mathrm{mg} / \mathrm{dl}$, $\mathrm{P}$ was $4.9 \mathrm{mg} / \mathrm{dl}, \mathrm{Mg}$ was $2.1 \mathrm{mg} / \mathrm{dl}$, and PTH was $171 \mathrm{pg} / \mathrm{ml}$. When last seen, in 2008, at the age of 24, she was feeling well except for occasional episodes of paresthesias, lightheadedness, and nausea, usually associated with poor compliance with the medication. Her Ca and PTH were, respectively, $8.6 \mathrm{mg} / \mathrm{dl}$ and $127 \mathrm{pg} / \mathrm{ml}$.

Patient 2, the younger half-sister of patient 1 (Fig. 2), was first seen in 2003, at the age of 1 year, because of obesity (length was $76 \mathrm{~cm}$; weight was $12.8 \mathrm{~kg}$ ) and weakness of the superior limbs. She was hypothyroid (TSH was $13.8 \mathrm{mU} / \mathrm{l}$; FT4 was $0.9 \mathrm{ng} / \mathrm{dl}$ ). Her serum ionized calcium was $4.45 \mathrm{mg} / \mathrm{dl}(\mathrm{nr}$ : $4.53-5.29 \mathrm{mg} / \mathrm{dl}$ ) and PTH was $26.3 \mathrm{pg} / \mathrm{ml}$. She initiated medication with thyroxine. At the last biochemical screening, in 2008, her Ca was $9.0 \mathrm{mg} / \mathrm{dl}$, P was $5.9 \mathrm{mg} / \mathrm{dl}$, and PTH was $401 \mathrm{pg} / \mathrm{ml}$ (Table 1). Currently, at the age of 6 , she is well developed and she is still on thyroxine.

Both patients had no stigmata of AHO.

The older sister of patient 1 , at the age of 26 , had normal $\mathrm{Ca}, \mathrm{P}$, and high PTH (86 pg/ml). No PHPrelated symptoms were observed in the remaining family members. 
Table 1 Relevant clinical and biochemical data on the patients

\begin{tabular}{llllllll}
\hline Patient & $\begin{array}{l}\text { Age at } \\
\text { diagnosis } \\
\text { (years) }\end{array}$ & Sex & $\begin{array}{l}\text { Calcium } \\
(8.9-10.0 \\
\mathrm{mg} / \mathrm{dl})\end{array}$ & $\begin{array}{l}\text { Phosphorus } \\
(2.3-4.7 \mathrm{mg} / \mathrm{dl})\end{array}$ & $\begin{array}{l}\text { PTH } \\
(12-65 \mathrm{pg} / \mathrm{ml})\end{array}$ & $\begin{array}{l}\text { Chvostek/ } \\
\text { Trousseau test }\end{array}$ & Brain CT \\
\hline Patient 1 & 11 & F & 4.8 & 10.5 & 566 & $+/+$ & Bilateral calcifications of the basal nuclei \\
Patient 2 & 6 & F & 9.0 & 5.9 & 401 & ND \\
Patient $3^{\text {a }}$ & 26 & F & 4.8 & 7.4 & 97 & $+/ \mathrm{ND}$ & $\begin{array}{c}\text { Abundant symmetric calcifications of the } \\
\text { thalamus and striatum }\end{array}$ \\
Patient $4^{\text {b }}$ & 44 & F & 6.9 & 4.5 & 269 & $-/+$ & Small calcification in the right lenticular nucleus \\
\hline
\end{tabular}

${ }^{a}$ Hypocalcemia was firstly detected at age 12, but initial biochemistry is not available

b Symptoms of hypocalcemia were first noticed at age 27, but initial biochemistry is not available

$P T H$ parathormone, $F$ female, $C T$ computed tomography, - negative, + positive, $N D$ not done

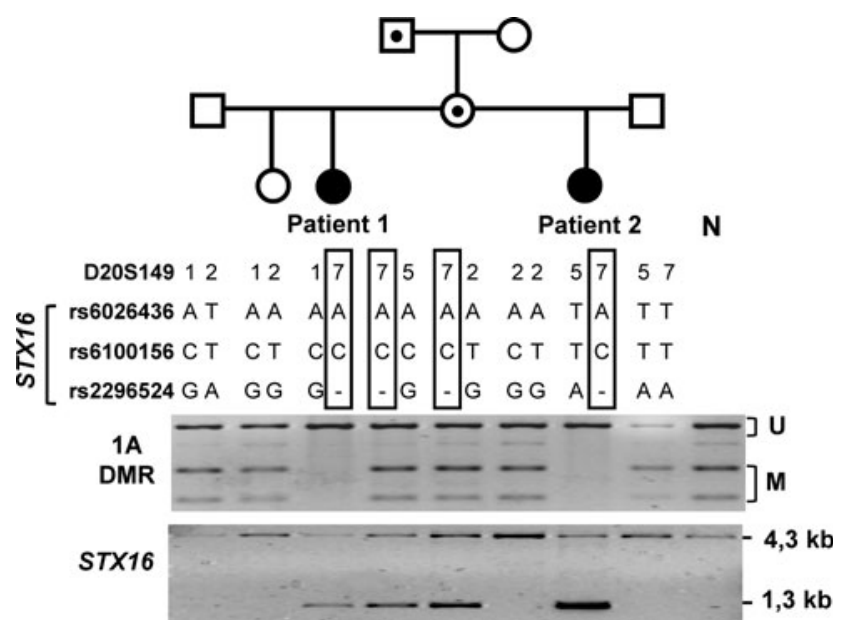

Fig. 2 Analysis of 1A differentially methylated region (DMR), and STX16 deletion screening in patients 1 and 2. PCR products from $1 \mathrm{~A}$ DMR were amplified from bisulfite-treated DNA from the patients, their relatives, and an unrelated normal individual $(\mathrm{N})$. In the absence of methylation, the sequence from the bisulfite-treated DNA is modified, removing the Bst $\mathrm{UI}$ recognition sites. Enzymatic digestion with BstUI results in fragments corresponding to the methylated alleles (M) while the undigested product corresponds to the unmethylated alleles (U). In patients 1 and 2, loss of methylation was detected at 1A DMR. Haplotype analysis using microsatellite markers and SNPs, flanking and encompassing the previously reported STX16 deleted regions at chromosome 20q13.3, identified a lack of maternal contribution at rs2296524 in patient 2. Long-range PCR amplification of a $4.3 \mathrm{~kb}$ fragment from the $S T X 16$ gene yielded a $1.3 \mathrm{~kb}$ mutant band in four family members, indicating that they were carriers of a previously reported $3.0 \mathrm{~kb}$ STX16 deletion. The haplotype segregating with the disease in this family is boxed. Open symbols represent unaffected individuals, closed symbols represent affected individuals, and dots indicate unaffected carriers of a mutant allele

Patient 3, a Caucasian female, was 11-year-old when, in 1985, she started complaining of "pins and needles", headaches, lightheadedness, and crises of tetany, during which she was unable to move her hands. She also had absence seizures. However, the first symptom that led her to medical attention occurred at the age of 12 , when, during a race, she started running in the opposite direction.
Hypocalcemia was diagnosed (no biochemical data from this time was available). Since then, she was treated with calcium and $1,25(\mathrm{OH})_{2} \mathrm{D}$ and the symptoms disappeared. At the age of 20, she discontinued the medication. She became pregnant at the age of 25 . Early in pregnancy, serum Ca was $6.8 \mathrm{mg} / \mathrm{dl}$ and $\mathrm{P}$ was $6.1 \mathrm{mg} / \mathrm{dl}$. These values went unheeded and no therapy was instituted. During pregnancy and most of the nursing period she felt well. After weaning, she started with crises of tetany similar to those she had while adolescent and she had a seizure. Her serum Ca, P, PTH, TSH, and total T4 were, respectively, $4.8 \mathrm{mg} / \mathrm{dl}, 7.4 \mathrm{mg} / \mathrm{dl}, 97 \mathrm{pg} / \mathrm{ml}, 5.4 \mathrm{mU} / \mathrm{l}$, and $9.3 \mu \mathrm{g} / \mathrm{dl}$ (T4 nr: $5.4-11.0 \mu \mathrm{g} / \mathrm{dl}$ ). CT scan of the brain revealed abundant symmetric calcifications in the thalamus and striatum. Chvostek sign was positive (Table 1). She was given calcium phosphate and $1,25(\mathrm{OH})_{2} \mathrm{D}$. The symptoms and Chvostek sign disappeared and she felt well. She became pregnant again at the age of 28 . The dosage of $1,25(\mathrm{OH})_{2} \mathrm{D}$ was increased. During pregnancy her average $\mathrm{Ca}, \mathrm{P}$, and PTH were, respectively, $7.8 \mathrm{mg} / \mathrm{dl}, 4.8 \mathrm{mg} / \mathrm{dl}$, and $23 \mathrm{pg} / \mathrm{ml}$. Throughout nursing, the dosage of $1,25(\mathrm{OH})_{2} \mathrm{D}$ was reduced, and her average $\mathrm{Ca}, \mathrm{P}$, and $\mathrm{PTH}$ were, respectively, $9.0 \mathrm{mg} / \mathrm{dl}, 4.8 \mathrm{mg} / \mathrm{dl}$, and $6.1 \mathrm{pg} / \mathrm{ml}$. After weaning, she resumed baseline therapy and has been well since. Her current BMI is $27 \mathrm{~kg} / \mathrm{m}^{2}$. No features of AHO were present. The biochemical screening for PHP in her parents was negative.

Patient 4 was a 44-year-old Caucasian female when first seen in 1997, at the Endocrinology Clinic, because of weight gain. Her height was $1.56 \mathrm{~m}$, weight $63 \mathrm{~kg}$ $\left(\mathrm{BMI}=25.9 \mathrm{~kg} / \mathrm{m}^{2}\right)$. She had been overweight since childhood. She had three children at the ages of 17, 23, and 25 years. Since the age of 27 , she had paresthesias of the face, superior limbs, and extremities that became worse with physical efforts. She also felt fatigue, myalgias, and depression. This condition was interpreted as fibromyalgia. She had no signs suggestive of AHO. On admission, her serum Ca, P, PTH, TSH, and FT4 were, respectively, $6.9 \mathrm{mg} / \mathrm{dl}, 4.5 \mathrm{mg} / \mathrm{dl}, 269 \mathrm{pg} / \mathrm{ml}, 2.9 \mathrm{mU} / \mathrm{l}$, and $0.96 \mathrm{ng} / \mathrm{dl}$. 
Chvostek sign was negative, but Trousseau was positive. Brain CT scan revealed a small calcification in the right lenticular nucleus (Table 1). She was treated with calcium and $1,25(\mathrm{OH})_{2} \mathrm{D}$. Currently, at the age of 53, she feels well. Her $\mathrm{Ca}$ is $8.3 \mathrm{mg} / \mathrm{dl}$ and her PTH levels are $114 \mathrm{pg} / \mathrm{ml}$. No PHP-related symptoms were observed in her first-degree family members.

\section{Methylation analysis of the GNAS locus}

This study was approved by the ethical committee of our institution. Venous blood or saliva was obtained from the patients and relatives, following written informed consent. DNA was extracted following standard methods, and modified with sodium bisulfite, using the Epitect Bisulfite kit (Qiagen, Hilden, Germany). The four GNAS DMRs (NESP55, AS, XL $\alpha$ s, and 1A) were amplified by Nested PCR and their differential methylation was assessed by restriction enzymatic analysis with $B s t \mathrm{UI}(\mathrm{CG} \downarrow \mathrm{CG})$ (New England Biolabs, Ipswich, MA, USA). Primer sequences and PCR conditions are available on request. The amplicons from DMRs 1A and NESP55 were cloned into the pCR2.1-TOPO vector, using the TOPO TA Cloning kit (Invitrogen, Paisley, PA, UK), and individual clones were sequenced. The methylation analyses were also performed in a normal unrelated individual (control).

\section{Analysis of STX16 gene and NESP55 DMR}

For haplotype analysis, single nucleotide polymorphisms (SNPs), located at the previously reported deleted regions of STX16 (5'-rs6026436, rs6100156, rs2296524-3') and NESP55 DMR (5'-rs4812038, rs3761264, rs1800900, rs1800905, rs55995056, rs3787497, rs6123832, rs4810147$3^{\prime}$ ), and at exon 5 from GNAS (rs7121), were PCR amplified, and sequenced. Flanking microsatellite markers (cenD20S149, STX16, GNAS, D20S443-tel) were also genotyped (NCBI; www.ncbi.nlm.nih.gov). DNA samples were screened for the STX16 $3.0 \mathrm{~kb}$ deletion, as previously described [11]. A $9.0 \mathrm{~kb}$ region, involving NESP55 DMR (from rs3761264 to rs4810147), was amplified using the LongRange PCR Kit (Qiagen, Hilden, Germany) to screen for deletions/insertions. Heterozygous SNPs were sequenced in this fragment to confirm amplification of both alleles. Smaller overlapping fragments, with sizes ranging from 1.5 to $5.0 \mathrm{~kb}$, were also amplified in this region. Primer sequences and PCR conditions are available on request.

\section{Results}

Differential methylation was assessed by restriction analysis with BstUI. Patients 1 and 2, whom were half-sisters, presented a loss of methylation at the maternal GNAS 1A DMR (Fig. 2). A normal methylation pattern was observed in the remaining DMRs, in the patients and relatives (data not shown). To investigate the genetic defect underlying this imprinting disruption, we screened the family for the 3.0 and $4.4 \mathrm{~kb}$ deletions, reported for the STX16 gene in familial cases [11, 13]. Haplotype segregation analysis at STX16 was not informative for patient 1 , because she was apparently homozygous for the three SNPs analyzed. However, this analysis revealed the absence of the maternal allele in patient 2, at rs2296524 (Fig. 2). Long-range PCR amplification showed that patients 1 and 2, their mother and grandfather, were carriers of the $3.0 \mathrm{~kb}$ deletion (Fig. 2).

In patients 3 and 4 , loss of methylation at $1 \mathrm{~A}$ and $\mathrm{AS}$ DMRs, and gain of methylation at NESP55 DMR, were identified in the maternal allele. Loss of methylation at the maternal XL $\alpha$ s DMR was observed only in patient 4. A normal methylation pattern was found in their family members (Fig. 3). Segregation analysis did not identify microdeletions at STX16 or NESP55 DMR in these two patients (Fig. 3). Long-range PCR amplification was also used to assess microdeletions. A fragment comprising 4.3 $\mathrm{kb}$ of the commonly deleted $3.0 \mathrm{~kb}$ region at STX16 was amplified in the two patients, and no mutant bands were detected (data not shown). A fragment encompassing $9.0 \mathrm{~kb}$ of NESP55 DMR was amplified in patients 3 and 4, and in three normal individuals, used as controls. In all amplifications, a single band was detected with the normal size (data not shown). The bands amplified from both patients DNA were sequenced, at two heterozygous polymorphic sites, which confirmed that both alleles were amplified (data not shown). In order to search for small deletions that could go unnoticed in a $9.0 \mathrm{~kb}$ gel band, smaller overlapping fragments, with sizes ranging from 1.5 to $5.0 \mathrm{~kb}$, were also amplified in this region, but no abnormal bands were detected for both patients (data not shown).

The broad methylation changes in patients 3 and 4, consistent with a paternal epigenotype in the maternal allele, could be the result of either a complete paternal isodisomy of chromosome 20 (inheritance of a duplicated copy from a single chromosome of the father) or a partial paternal isodisomy encompassing the GNAS locus, or NESP55 DMR only [15]. Eight SNPs spanning an $\sim 10 \mathrm{~kb}$ region, which included NESP55 DMR, were genotyped in these two patients (Fig. 3). Four of these SNPs (rs1800900, rs1800905, rs55995056, and rs3787497) were located within an $\sim 4.0 \mathrm{~kb}$ region, which has been suggested to carry a control element for the GNAS imprinting [14]. Both patients were heterozygous for several SNPs, including those located at the $4.0 \mathrm{~kb}$ region. Furthermore, these patients were also heterozygous for a 5-bp repeat at $1 \mathrm{~A}$ DMR (Fig. 4). Therefore, it 


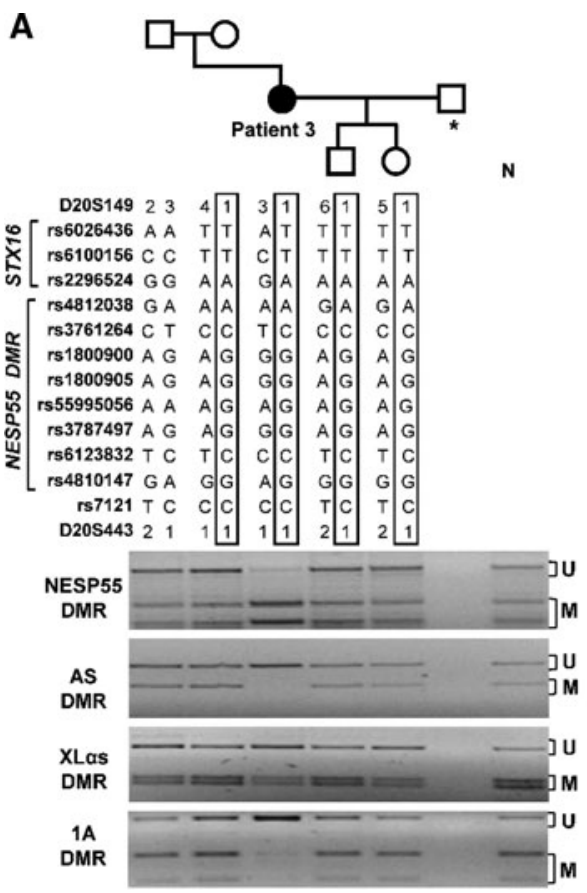

Fig. 3 Analysis of GNAS differentially methylated regions (DMRs), and haplotype segregation analysis at STX16/GNAS loci, in patients 3 and 4. PCR products from each DMR were amplified from bisulfitetreated DNA from the patients, their relatives, and an unrelated normal individual $(\mathrm{N})$. In the absence of methylation, the sequence from the bisulfite-treated DNA is modified, removing the Bst $\mathrm{UI}$ recognition sites. Enzymatic digestion with Bst $\mathrm{UI}$ resulted in fragments corresponding to the methylated alleles (M) while the undigested product corresponds to the unmethylated alleles (U). a Haplotypes for STX16/GNAS loci are shown for patient 3 and her family, and the patient's maternal haplotype is boxed. In patient 3,

seems unlikely that these patients carry either a complete isodisomy at chromosome 20, or a partial isodisomy at GNAS locus, or NESP55 DMR only.

Paternal heterodisomy (inheritance of both chromosomes from the father) at chromosome 20 could also account for the abnormal GNAS methylation pattern in the patients 3 and 4 [16]. However, in patient 3, biparental inheritance at STX16/GNAS excluded heterodisomy (Fig. 3a). In patient 4 , given that the DNA from her father was not available to study, paternal heterodisomy, involving the entire chromosome 20 , could only be excluded by the detection of a normal methylation status at the imprinted NNAT gene [17], located at chromosome 20q11.2-q12 (data not shown).

Regarding the inheritance of the affected alleles, both offspring of patient 3 shared a maternal haplotype covering STX16 and GNAS, transmitted by the grandmother. However, they did not present GNAS methylation changes (Fig. 3a). The son of patient 4, who inherited the STX16GNAS haplotype, transmitted by the maternal grandmother, did not present methylation changes either (Fig. 3b).

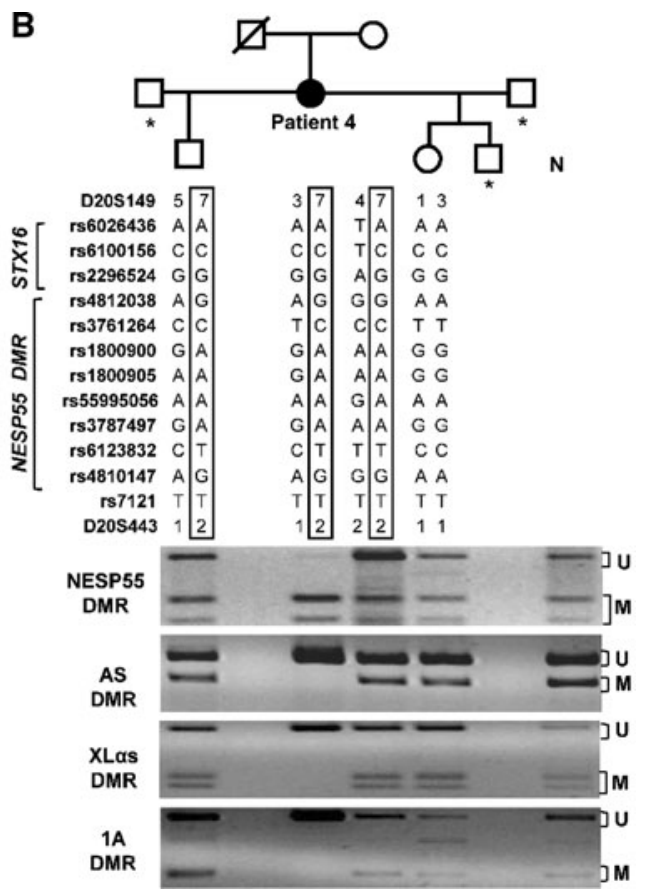

gain of methylation at NESP55 DMR and loss of methylation at AS and 1A DMRs were detected, at the maternal allele, whereas the methylation status of XL $\alpha$ s DMR appeared unchanged. The patient's relatives presented a normal methylation pattern. b Haplotypes for STX16/GNAS loci are shown for patient 4 and her family, and the boxed haplotype represents the patient's maternal haplotype. Patient 4 had loss of methylation at AS, XL $\alpha$ s, and 1A DMRs and gain of methylation at NESP55 DMR. The patient's mother and offspring showed a normal methylation pattern. Open symbols represent unaffected individuals, closed symbols represent affected individuals, and asterisks indicate individuals that were not investigated

The methylation changes found at 1A and NESP55 DMRs, in patients 1,3 , and 4 , were confirmed and extended, by cloning the same amplicons and sequencing all CpGs (Fig. 4).

The identification of imprinting defects at the GNAS locus confirmed the diagnosis of PHP-Ib in the four patients.

\section{Discussion}

In this study, we identified three unrelated patients presenting hypocalcemia, hyperphosphatemia, elevated serum levels of PTH, and no visible features of AHO, suggesting the diagnosis of PHP-Ib. An affected oligosymptomatic sister was also identified (patient 2). In order to investigate the molecular defects underlying PHP in these patients, a comprehensive analysis of GNAS and STX16 loci was undertaken.

Loss of methylation was detected at GNAS 1A DMR, in patients 1 and 2, resulting from the autosomal dominant 


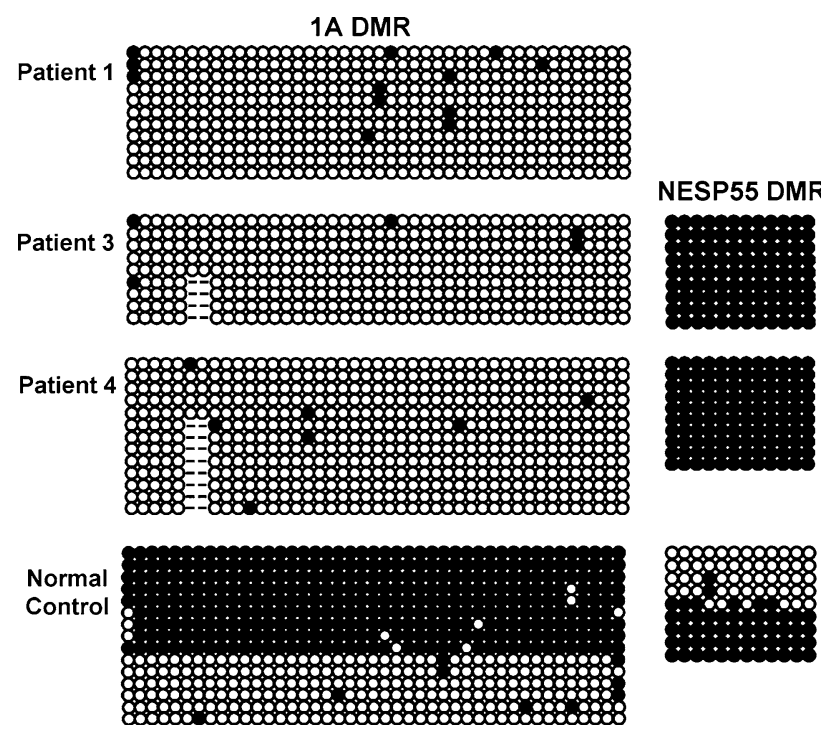

Fig. 4 Characterization of methylation defects in the $\mathrm{CpG}$ islands from 1A and NESP55 differentially methylated regions (DMRs) in patients 1,3 , and 4 . Since both patients 1 and 2 inherited the same genetic defect (STX16 deletion), the epigenetic alteration at 1A DMR was not further characterized in patient 2 . PCR products from $1 \mathrm{~A}$ DMR, amplified from bisulfite-treated DNA, were cloned and sequenced for extended methylation analysis. Each row of circles represents one clone. Methylated CpGs are indicated by closed circles and unmethylated CpGs by open circles. In patients 1,3 , and 4 , a loss of methylation in 1A DMR was shown by the predominance of unmethylated CpGs in all the clones. Patients 3 and 4 were heterozygous for a 5-bp repeat polymorphism that includes two additional CpGs, represented by two circles. Patient 1 and the normal control were homozygous for this polymorphism. The analysis of CpG methylation was extended to NESP55 DMR in patient 3 and patient 4 . In both cases, methylation was observed in all clones sequenced, indicating a gain of methylation at NESP55 DMR. A normal methylation pattern was observed in the unrelated normal individual, in whom the sequenced clones revealed the presence of methylated and unmethylated alleles, for both 1A and NESP55 DMRs

inheritance of a previously reported $3.0 \mathrm{~kb}$ deletion in the STX16 gene, comprising a putative cis-acting control element for the imprinting of the GNAS locus [11]. The paternal inheritance of the deletion in their mother and, possibly, in the grandfather, explains the lack of methylation defects in these two unaffected carriers. In patients 3 and 4, methylation changes were detected at DMRs NESP55, AS, 1A and, also at XL $\alpha$ s, in patient 4, consistent with a paternal epigenotype in the maternal allele. This suggested either a familial form of PHP-Ib, associated with NESP55 DMR deletions, or a sporadic manifestation of the disease $[9,14,15]$. However, we found no evidence that these patients carried deletions at STX16 or NESP55 DMR. Haplotype analysis showed that both offspring of patient 3, and the son of patient 4 , inherited the grandmaternal alleles at the STX16/GNAS loci, but did not present GNAS imprinting changes. These results point to several different possibilities regarding the genetic mechanism causing imprinting disruption in the two patients: (a) a putative mutation located at another, yet unidentified, locus distant from the GNAS chromosomal region; (b) a post-zygotic mutation at the STX16/GNAS loci, leading to mosaicism; (c) a failure in the imprinting erasure and reset at the maternal germ cells; and (d) a complete or partial paternal iso/heterodisomy at chromosome 20 .

The hypothesis of either a complete isodisomy at chromosome 20, or a partial isodisomy at the GNAS locus, or NESP55 DMR only, is poorly sustained by the haplotype data, since heterozygosity was identified for several polymorphisms located at a $10 \mathrm{~kb}$ region encompassing NESP55 DMR, and also 1A DMR. The possibility of a paternal heterodisomy of chromosome 20 was ruled out in patient 3, by the biparental inheritance of alleles at STX16/ GNAS and, in patient 4, by the detection of a normal methylation status at the imprinted NNAT gene. However, since NNAT is located centromeric to GNAS, a telomeric paternal heterodisomy encompassing the GNAS locus could not be excluded in patient 4. Indeed, patients with imprinting disorders, carrying biparental alleles with segmental heterodisomy, have been previously reported [16].

As regards to the clinical onset of the disease, in patients 1 and 3, hypocalcemia was first observed at the ages of 1112 years. Patient 2 , at the age of 6 , had normal calcium levels but her PTH was already very high. In patient 4 , nonspecific symptoms started by the age of 27 , but hypocalcemia was only detected at the age of 44 . A review of published clinical data of patients with PHP-Ib revealed that the mean age of diagnosis is $11.6 \pm 1.60$ years in symptomatic female patients, carrying the $3.0 \mathrm{~kb}$ maternal deletion at STX16, and $9.5 \pm 1.06$ years in female sporadic patients [18]. The reasons why the resistance to PTH and hypocalcemia develop only at a certain age are unclear. Patient 1 had a normal concentration of $1,25(\mathrm{OH})_{2} \mathrm{D}$ at a time when she was frankly symptomatic and hypocalcemic. A similar case was reported by Bastepe et al. [15]. These are noteworthy findings, considering that most patients with pseudohypoparathyroidism present with low concentrations of $1,25(\mathrm{OH})_{2} \mathrm{D}$, as expected from the reduced responsiveness of their proximal tubules to PTH $[1,2]$. The older sister of patients 1 and 2 presented mildly elevated levels of PTH, together with normocalcemia, at the age of 26. Establishing a non-carrier status in this patient was important, as it showed that, rather than PHP-Ib, the high PTH levels were probably due to secondary hyperparathyroidism.

Two of the four patients in the present series (patients 1 and 2) had subclinical hypothyroidism, possibly due to resistance to TSH. An overall analysis of the clinical features associated to the defective GNAS imprinting shows a consistent pattern concerning the symptoms associated to PTH resistance $[11,18]$. However, additional manifestations of hormone resistance (e.g., TSH), related to tissue- 
specific imprinting of $\mathrm{G}_{\mathrm{s}} \alpha$, are variable or absent among PHP-Ib patients, as shown in this, and other reports [12, 19].

This study describes the first clinical and genetic characterization of Portuguese patients with PHP-Ib. The identification of imprinting defects allowed the differential diagnosis between PHP-Ib and other PHP variants. Since clinical and biochemical findings can be quite variable, mildly affected or young asymptomatic patients with PHPIb may not be readily identified. As shown in this study, the identification of hereditary forms of PHP-Ib is important for clinical management and genetic counseling. The detection of a STX16 deletion in patients 1 and 2 indicated that their offspring will have a $50 \%$ chance of inheriting the disease. On the other hand, since the mechanisms underlying broad GNAS methylation changes in patients 3 and 4, are still unknown, as in most apparently sporadic cases, the presence of germline alterations in distinct loci cannot not be ruled out. Nonetheless, the absence of methylation defects in these patients' offspring allowed their exclusion from further clinical screening.

Further genetic studies on PHP-Ib cases are needed to unveil novel somatic and germline events involved in the control of GNAS imprinting.

Acknowledgments The authors are grateful to the families for their cooperation. This work was supported by Associação de Endocrinologia Oncológica.

\section{References}

1. M. Bastepe, H. Jüppner, Horm. Res. 63, 65-74 (2005)

2. G. Mantovani, A. Spada, Best Pract. Res. Clin. Endocrinol. Metab. 20, 501-513 (2006)
3. F. Albright, C.H. Burnett, P.H. Smith, W. Parson, Endocrinology 30, 922-932 (1942)

4. B.E. Hayward, M. Kamiya, L. Strain, D.T. Bonthro, Proc. Natl. Acad. Sci. USA 95, 10038-10043 (1998)

5. S.F. Wroe, G. Kelsey, J.A. Skinner, D. Bodle, S.T. Ball, C.V. Beechey, J. Peters, C.M. Williamson, Proc. Natl. Acad. Sci. USA 97, 3342-3346 (2000)

6. S. Yu, D. Yu, E. Lee, M. Eckaus, R. Lee, Z. Corria, D. Accili, H. Wesphal, L.S. Weinstein, Proc. Natl. Acad. Sci. USA 95, 87158720 (1998)

7. G. Mantovani, E. Ballare, E. Giammona, P. Beck-Peccoz, A. Spada, J. Clin. Endocrinol. Metab. 87, 4736-4740 (2002)

8. J. Liu, D. Litman, M.J. Rosenberg, S. Yu, L.G. Biesecker, L.S. Weinstein, J. Clin. Invest. 106, 1167-1174 (2000)

9. J. Liu, J.G. Nealon, L.S. Weinstein, Hum. Mol. Genet. 14, 95$102(2005)$

10. J. Liu, M. Chen, C. Deng, D. Bourc'his, J.G. Nealon, B. Erlichman, T.H. Bestor, L.S. Weinstein, Proc. Natl. Acad. Sci. USA 102, 5513-5518 (2005)

11. M. Bastepe, L.F. Fröhlich, G.N. Hendy, O.S. Indriadason, R.G. Josse, H. Koshiyama, J. Körkkö, J.M. Nakamoto, A.L. Rosenbloom, A.H. Slyper, T. Sugimoto, A. Tsatsoulis, J.D. Crawford, H. Jüppner, J. Clin. Invest. 112, 1255-1263 (2003)

12. G.P. de Nanclares, E. Fernández-Rebollo, I. Santin, B. GarcíaCuartero, S. Gaztambide, E. Menéndez, M.J. Morales, M. Pombo, J.R. Bilbao, F. Barros, N. Zazo, W. Ahrens, H. Jüppner, O. Hiort, L. Castaño, M. Bastepe, J. Clin. Endocrinol. Metab. 92, 23702373 (2007)

13. A. Linglart, R.C. Gensure, R.C. Olney, H. Jüppner, M. Bastepe, Am. J. Hum. Genet. 76, 804-814 (2005)

14. M. Bastepe, L.F. Fröhlich, A. Linglart, H.S. Abu-Zahra, K. Tojo, L.M. Ward, H. Jüppner, Nat. Genet. 37, 25-27 (2005)

15. M. Bastepe, A.H. Lane, H. Jüppner, Am. J. Hum. Genet. 68, 1239-1283 (2001)

16. S. Nazarenko, E. Sazhenova, A. Baumer, A. Schinzel, Eur. J. Hum. Genet. 12, 411-414 (2004)

17. H.K. Evans, A.A. Wylie, S.K. Murphy, R.L. Jirtle, Genomics 77, 99-104 (2001)

18. A. Linglart, M. Bastepe, H. Jüppner, Clin. Endocrinol. 67, 822831 (2007)

19. J. Liu, B. Erlichman, L.S. Weinstein, J. Clin. Endocrinol. Metab. 88, 4336-4341 (2003) 